\title{
Louviers - Route de la Vacherie
}

$\mathrm{n}^{\circ} 17-2280$

Maud Le Saint Allain

\section{(2) OpenEdition}

Journals

Édition électronique

URL : http://journals.openedition.org/adlfi/16629

ISSN : 2114-0502

\section{Éditeur}

Ministère de la culture

Référence électronique

Maud Le Saint Allain, «Louviers - Route de la Vacherie », ADLFI. Archéologie de la France - Informations

[En ligne], Haute-Normandie, mis en ligne le 18 février 2016, consulté le 19 avril 2019. URL : http:// journals.openedition.org/adlfi/16629

Ce document a été généré automatiquement le 19 avril 2019

(c) Ministère de la Culture et de la Communication, CNRS 


\title{
Louviers - Route de la Vacherie
}

$n^{\circ} 17-2280$

\author{
Maud Le Saint Allain
}

\author{
Lien Atlas (MCC) : \\ http://atlas.patrimoines.culture.fr/atlas/trunk/index.php? \\ ap_theme=DOM_2.01.02\&ap_bbox=1.106;49.192;1.205;49.250
}

1 Un projet de lotissement a donné lieu à un diagnostic archéologique sur une surface de $42700 \mathrm{~m}^{2}$. Les parcelles explorées sont situées partiellement sur le coteau de la forêt de Bord et au départ du fond de vallée.

2 Les découvertes se résument, sur les parties hautes, à la mise au jour partielle du plan d'un établissement quadrangulaire de l'âge du Fer. D'une superficie connue de $1000 \mathrm{~m}^{2}$, la suite de l'enclos se développe dans les parcelles adjacentes non concernées par les aménagements. Si l'aire interne n'a pas livré de vestige de construction, le comblement des fossés au nord a permis, par la présence de mobilier céramique, de scories de fer et de quelques objets métalliques, de conforter la nature domestique de cet établissement et son attribution chronologique à La Tène au sens large. Les parcelles les plus au sud sont quant à elles marquées par un épais niveau de colluvions historiques, pouvant atteindre par endroit une puissance de deux mètres. Aucun vestige n'a été repéré, à l'exception de perturbations non caractérisées et de quelques parcellaires d'époque récente. Le mobilier retrouvé sporadiquement dans ces colluvions, sur la base d'un éperon à molette, atteste une fréquentation des lieux au plus tôt au $\mathrm{xVI}^{\mathrm{e}} \mathrm{s}$. 


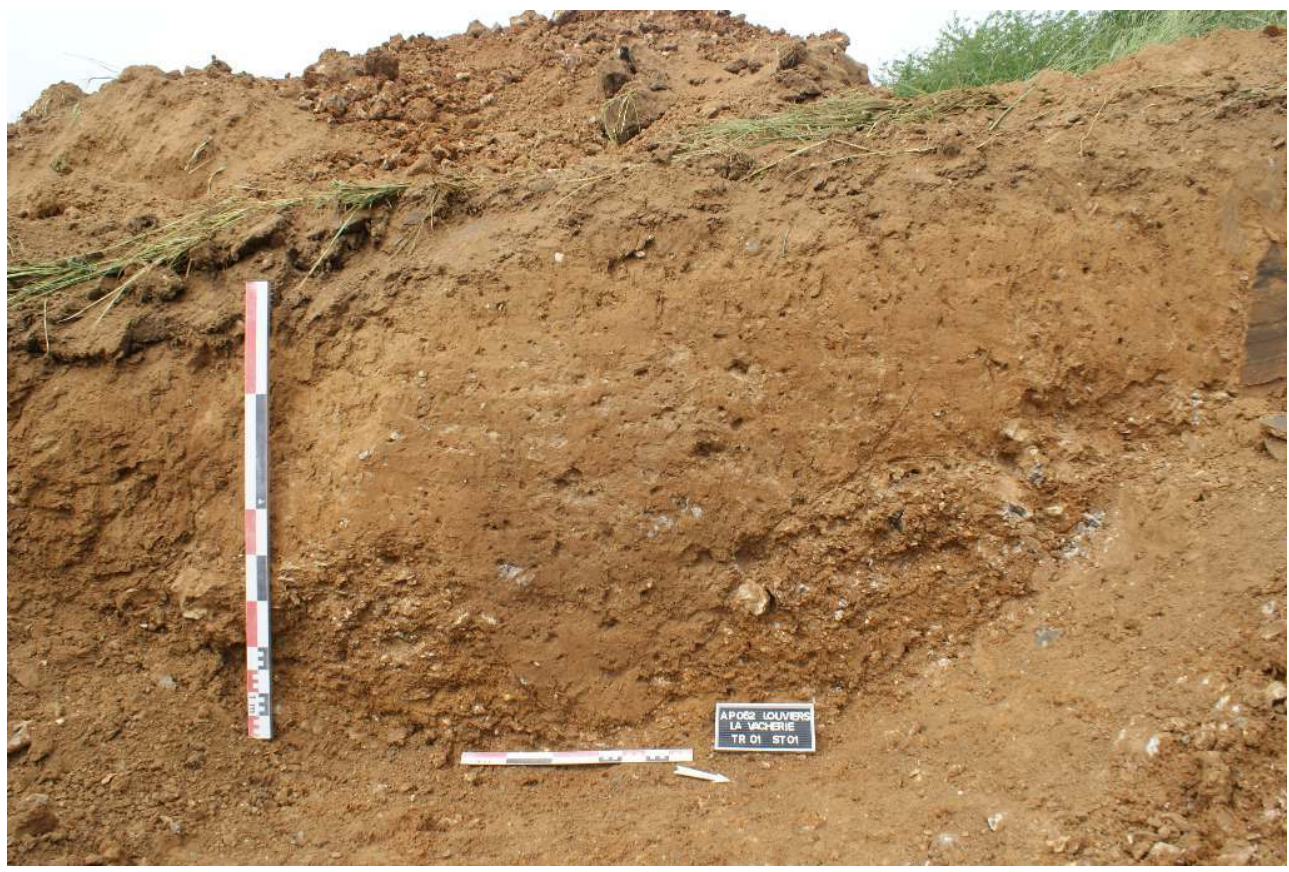

Fig. 1

Jatte de l'âge du Fer

M. Le Saint Allain

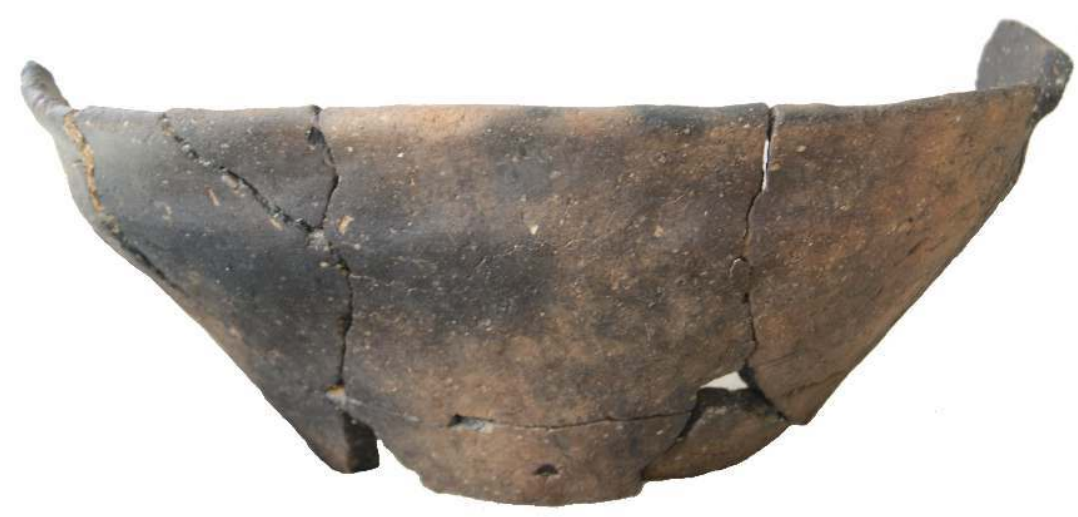

Fig. 2

Fossé laténien

M. Le Saint Allain 
INDEX

Index chronologique : âge du Fer operation Diagnostic (EV)

Mots-clés : fossé, enclos, éperon à molette, scories, jatte Index géographique : Normandie, Eure (27), Louviers

\section{AUTEURS}

\section{MAUD LE SAINT ALLAIN}

Mission Archéologique de l'Eure 